This item was submitted to Loughborough's Research Repository by the author.

Items in Figshare are protected by copyright, with all rights reserved, unless otherwise indicated.

\title{
Rethinking the effectiveness of defecation postures and practices: it's not what you do it's the way that you do it!
}

PLEASE CITE THE PUBLISHED VERSION

https://doi.org/10.3362/1756-3488.17-00019

\section{PUBLISHER}

(C) Practical Action Publishing

\section{VERSION}

AM (Accepted Manuscript)

\section{PUBLISHER STATEMENT}

This work is made available according to the conditions of the Creative Commons Attribution-NonCommercialNoDerivatives 4.0 International (CC BY-NC-ND 4.0) licence. Full details of this licence are available at: https://creativecommons.org/licenses/by-nc-nd/4.0/

\section{LICENCE}

CC BY-NC-ND 4.0

\section{REPOSITORY RECORD}

Edgar, Charles, M Sohail, and Sue Cavill. 2019. "Rethinking the Effectiveness of Defecation Postures and Practices: It's Not What You Do It's the Way That You Do It!". figshare. https://hdl.handle.net/2134/26761. 


\title{
Rethinking the effectiveness of defecation postures and practices: it's not what you do it's the way that you do it!
}

\author{
Charles Edgar, M. Sohail and Sue Cavill
}

\section{Introduction}

Although we have set international targets to achieve access to adequate and equitable sanitation and hygiene for all by 2030 (UN, 2015), how we defecate and clean ourselves afterwards is rarely discussed.

Defecation is the discharge of faeces from the body (Oxford Dictionary, 2010). The process of defecation usually involves three components (a) involuntary waves of contraction of the rectum (b) smooth muscle relaxation of the anal canal with an increased anorectal angle (c) straining of the abdominal muscles to expel faeces (Ahmed et al, 2013). Most people either squat or sit to shit. Sitting on a pedestal toilet is the typical practice in much of Europe and North America, whereas squatting is more common in Africa and Asia although squat toilets are also used in European countries. The pedestal toilet involves the user sitting with an upright posture on a chair-like structure with knees at right angles (dependant on height of seat and the individual). In contrast, to use a squat toilet, the user must perform a deep squat, sometimes hugging their knees, in order to position themselves appropriately to shit into the hole.

The literature on posture for defecation has long recommended that if the hip joints are flexed (as in a squat position) this will increase the anorectal angle, straightening the anal canal, and thereby increasing the ease of defecation. When sitting on the toilet, the anorectal angle is only partially straight, making straining necessary for evacuation. Over time, conditions associated with straining to defecate include haemorrhoids, rectal prolapse, diverticula and rectal fissures (NHS Direct). Such conditions have led to more people in Europe and North America adapting their postures by using a footstool to raise the knees (and thus flex the hip joints) when seated on a pedestal toilet. Squatting reduces the time required for defecation, the level of 'expulsive effort' and promotes a more complete feeling of bowel emptying (Sikirov, 2003; Williams and Wetherill, 1950; Kira 1976; Taggart, 1966; Ahmed, Shabbir, Iqbal and Najam 2013).

Anal cleansing practices are linked to defecation postures. It is assumed that 'sitters' generally wipe whereas squatters usually wash (von Münch and Milosevic, 2015). Methods of anal cleansing typically involve the use of water (sometimes followed by toilet paper/other material for drying), or the use of toilet paper/other material (such as newspaper, corn cobs etc. where toilet tissues are not available due to cost) alone. However, the anus can be hard to clean after a bowel movement, due to its shape, leading to the possibility of faeces becoming trapped in the folds of skin around the anus. Whilst there is a significant amount of literature on hand contamination as a result of cleaning the anus after defecation, there is very little evidence on the most effective method for cleaning the anus and buttocks after defecation. If the area isn't cleaned properly, faecal matter left behind on the skin can cause itch/irritation, it can result in smell and soiling of underwear/clothing.

\section{Research study}

A study to investigate the effectiveness of defecation postures and anal cleaning method was performed at Loughborough University. The research compared how long each bowel movement took on a pedestal toilet with and without a footstool. 33 healthy volunteers were asked to compare the two positions for speed as well as stress/strain on the body. The effectiveness of the method of anal cleansing was also rated by a sub-set of the volunteers.

Of the 33 volunteers, 24 were males and 9 females, with an age range of 18-51 years and a normal bowel function agreed to take part. The volunteers were staff or students of Loughborough 
University. The study involved volunteers with lifelong experience of using a toilet and wiping for anal cleansing. Ethical research clearance was received from Loughborough University Ethics Approvals (Human Participants) Sub-Committee. All subjects gave written informed contest before participating in the study, and none had a previous history of abdominal or pelvic surgery, anal fissure, pain or infections. None of the volunteers had to be excluded from the test due to diarrhoea, incontinence or bowel movements of less than three times per week. Volunteers provided information on their diet, which ranged from vegan to vegetarian and meat-eating diets. The volunteers were instructed not to change their diet. Although data was collected on the diets of volunteers the findings are not disaggregated by diet. Volunteers confirmed that they were able to assume either of the positions expected of them on the toilet.

Volunteers were asked to record the time it took to empty their bowels in 2 different positions: (1) a seated posture on a pedestal toilet and (2) in a seated position on the pedestal toilet but with the feet raised through use of a footstool, to mimic the squat position This allowed the participant to raise their feet by $20 \mathrm{~cm}$ such to encourage a position closer to the squatted position while still occupying a raised toilet. Footstools were provided to the participants by the investigation team. Participants used stopwatches, also provided by the investigation team, to record the time it took for them to defecate in the two positions. They were instructed to start the stopwatch when their bottom made contact with the toilet seat and instructed to stop the stopwatch when they felt that they had reached an adequate level of bowel emptiness. All participants performed the test 6 times in each position. The participants performed the tests on their toilets at home.

Volunteers were also asked to grade the ease of their bowel movement in the two positions on a scale of 1-3, whereby 1 meant the bowel movement was easy, 2 implied it was moderate and 3 was a strenuous activity.

8 of the 33 volunteers agreed to participate in a further study of anal cleansing, the other volunteers were unwilling to participate. All those that agreed to perform the test were males and aged between 20 and 21 years old. All the volunteers were habitual wipers, although one participant had a single previous experience washing. These 8 volunteers were asked to clean their peri-anal skin with toilet paper after defecation as usual and, when they thought they were clean, they were asked to wipe again once with a wet wipe. The volunteers then recorded whether faecal matter was present on the wipe. The investigation team supplied the wet wipes to the volunteers.

Our study found that:

- Time: The average time taken to defecate in the seated position on a pedestal toilet was 113.4 seconds. When participants used a footstool the average defecation time was 55.5 seconds, which indicates that using a footstool resulted in quicker bowel movements. The time saved ranged between 190.3 seconds to 0.2 seconds with the average time saved as 57.9 seconds.

- Effort: The volunteers grading of the effort/strain required to defecate was 2.5 in a seated position (i.e. moderate) and 1.4 when using the footstool (i.e. easy). All but one of the volunteers found that the use of the footstool resulted in less strenuous method of defecation.

- Effectiveness of anal cleansing: The investigation of anal cleansing showed that 6 of the 7 subjects found residual faecal matter on a wet wipe after they thought the area was adequately cleansed with toilet paper. Thus, toilet paper alone did not fully remove all faecal matter from around the anus.

Our study confirms the findings of other research (Sikiov, 2003) that using a footstool to achieve a squat-like position whilst sitting on a toilet reduced the duration and laborious process of defecation. It also showed that life-long 'wipers' were not completely clean after using toilet paper to wipe themselves after defecation. The results suggest that adopting a squat-like position and combining washing with wiping for anal cleansing may prove more effective practices. These findings have a number of global implications for sanitation marketing and hygiene promotion programmes. 


\section{Discussion}

Although the study was conducted using volunteers in the UK, attention to defecation postures and effectiveness of anal cleansing have international relevance for sanitation marketing and hygiene promotion programmes and wellbeing in terms of the speed and strain on the body as well as hygiene practices. While squat toilets (such as pour flush or pit latrines and composting toilet) are categorised as an improved sanitation technology, providing for the safe management and disposal of faeces, a toilet with a pedestal is seen by many around the world as a more aspirational toilet. "The trend setters who define conventions for slum and urban societies in developing countries are the often wealthier, well-travelled, better educated members of the community. Slum dwellers, when asked about their toilet preferences always answer, without exception, a Western style flush-and-forget type toilet" (Sugden, 2014). Similarly, von Münch and Milosevic (2015) report on a survey of sanitation professionals and practitioners (contacted via the SuSanA Discussion Forum) on the use of squatting toilets in different countries. They found a trend in countries such as India, Indonesia, Malaysia, Nepal, Pakistan, Thailand, Kenya, Rwanda, Somalia, Tanzania and Uganda towards more sitting toilets, especially in urban (wealthy) areas. Sugden (2014) also notes a possible gradual shift has been noted with the middle class urban population of Africa towards the sitting position. Increasingly, pedestal toilets - or installing a makeshift seat - are recommended as more convenient for those less able to squat such as older people, pregnant women or people with a disability (Jones and Reed, 2005; Jones and Wilbur, 2014; von Münch and Milosevic, 2015). Such aspirations and motivators are used to drive sanitation marketing and incorporated in human centred design to make latrines more desirable (e.g. Ghana's Clean Team service and Sama Sama toilet or the Easy Latrine in Cambodia) that 'gave people what they wanted' (WSP, 2012 quoted in Dumpert and Perez, 2015). However, developing a product that meets the customer's high-end expectations and aspirations may not always achieve customer satisfaction. Our study suggests that alongside aspiration, demand creation efforts must also consider how anatomical position can help the physiology of defecation adopting a seated position affects the ease of defecation, particularly for those with conditions like constipation that are more common in older adults and during pregnancy.

Ease and frequency of bowel movements is an indicator of physical health. Less attention, however, has been directed towards understanding wellbeing and the mental and social consequences of changing defecation practices. "When someone is used to using a special type of toilet, suddenly changing his or her habit puts severe psychologic stress on the person and evacuation may not be complete in the new method" (Rad, 2002). This condition is termed parcopresis, psychogenic faecal retention or shy bowel. Anecdotally 'shy bowel' is reported to be a factor when individuals resist the use of newly built latrines in communities on the path to becoming Open Defecation Free (ODF) (Cavill, personal communication). The SQUAT survey in Northern India found that of those with a toilet who continued to defecate in the open, 74 per cent found it pleasurable, comfortable or convenient (Coffey et al 2014). Older people's reluctance to abandon the habit of open defecation sometimes considering it healthier- can be a barrier to achieving ODF status (Chambers and Myers, 2016). Resistance to changing customary defecation positions is also observed in the UK: when Nile pans were installed in a public toilet (alongside the pedestal toilets) in a shopping centre in Rochdale, there was a public outcry one tabloid reported that 'Council wastes YOUR money on hole-in-ground toilets' and described them as 'Muslim only public loos' (BBC, 2010; Islamaphobia Watch, 2010).

For a sector concerned with hygiene promotion there is surprisingly little literature available on approaches to anal cleansing. Yet, anal cleansing is an essential part of hygiene to avoid skin irritation, smell, or urinary tract infections. Yet the topic is neglected (McMahon, 2011; Sidibe and Curtis, 2007; WSP, 2005). Hygiene promotion campaigns rarely refer to how to perform anal cleaning effectively. There is an assumption that once people stop open defecation, they don't need to improve how they wash or wipe in terms of their technique (wiping from front to back to avoid infections) or the right amount of paper/water to use (and to check the paper and if it's not clean to wipe/wash again). Yet our study found that even habitual wipers aren't cleaning themselves effectively. Clearly there is room for improvement and companies have seen a gap in the market. Advertising in Europe and North America for commercially available moistened tissues/wipes claim to help people feel more completely clean and fresh when they wipe themselves. 
As WASH professionals, we have a responsibility to promote the personal health, dignity and wellbeing associated with defecation and not just the technical options to stop open defecation. Let's start with the following:

- Globally more attention to anal cleansing practices and preferences is necessary in order to understand this aspect of hygiene behaviour. Anal cleansing should be included as a routine part of hygiene promotion efforts, alongside handwashing with soap, menstrual hygiene, and bathing.

- In low-income countries, access to anal cleaning materials in household, public and community latrines must be a priority if these sanitation improvements are to truly affect those assumed to benefit.

- In low-income contexts, further research and development (iterative learning, prototyping and refining solutions as part of Human Centred Design) is needed to help the 'sitter' on pedestal toilets to achieve the best position to support evacuation of the bowels - with or without the benefit of a footstool. This is of particular importance to vulnerable groups who use a seat because they can no longer squat. It also requires more attention to how this product can be made an aspirational consumer item that reflects consumer preferences (in addition to developing a supply chain and business model).

- The importance of defecation position to wellbeing has been under-researched to date. New research should seek to understand how moving from a squat to a seated position - as a result of ending open defecation, upgrading a sanitation facility or through the inability to squat - affects the individual's physical, mental, and social experience of defecation. It is expected to be particularly important for those prone to constipation or other conditions affecting bowel movements.

\section{References}

Ahmed, Imtiaz., Muhammad Najmuddin Shabbir, Mohammad Ali lqbal, Muhammad Shahzeb Najam (2013) Role of defecation postures on the outcome of chronic anal fissure Pak J Surg 2013; 29(4):269271. http://www.pjs.com.pk/journal_pdfs/oct-dec13/269.pdf [Accessed $10^{\text {th }}$ August, 2017]

BBC (2010) Squat toilets in Rochdale shopping centre: http://www.bbc.co.uk/news/uk-englandmanchester-10644118 [Accessed $10^{\text {th }}$ August, 2017]

Chambers, R. and Myers, J. (2016) 'Norms, Knowledge and Usage', Frontiers of CLTS: Innovations and Insights Issue 7, Brighton: IDS:

https://opendocs.ids.ac.uk/opendocs/bitstream/handle/123456789/8960/Issue7_Norms_knowledge _and_usage_2ndEdition.pdf?sequence $=3$ [Accessed $10^{\text {th }}$ August, 2017]

Coffey, D., Gupta, A., Hathi, P., Khurana, N., Spears, D., Srivastav, N. and Vyas, S. (2014) Revealed Preference for Open Defecation: Evidence from a New Survey in Rural North India, SQUAT Working Paper 1, Rice Institute, http://riceinstitute.org/wordpress/wp-content/uploads/downloads/2014/09/ SQUAT-paper-for-mailing-and-website_062414.pdf

Dumpert, James and Eddy Perez (2015) Going beyond mason training: enabling, facilitating and engaging rural sanitation markets for the base of the pyramid. Waterlines Jul 2015, Vol. 34, Issue 3, pp. 210-226

Edgar, Charles (2016) "Squatting vs Sitting 7 Washing vs Wiping; are United Kingdom citizens correct in the way in which they use a toilet." A Dissertation submitted in partial fulfilment of the requirements for the award of Bachelor of Science of Loughborough University, May 2016 
Han, Aung Myo., Khin New Do, Tin Aye, Thein Hlaing (1986) Personal toilet after defaecation and the degree of hand contamination according to different methods used. J Trop Med Hyg. 1986 Oct;89 (5):237-41.

Islamaphobia Watch: PCC upholds complaint against Daily Starr over 'Muslim-only public loos' story Bob Pitt, September 26, 2010 http://www.islamophobiawatch.co.uk/2010/?w=38 [Accessed $10^{\text {th }}$ August, 2017]

Jones $\mathrm{H}$ and Reed R (2005) Water and sanitation for disabled people and other vulnerable groups: designing services to improve accessibility. WEDC, UK. https://wedc- knowledge.lboro.ac.uk/d etails.html?id=16357 [Accessed $10^{\text {th }}$ August, 2017]

Jones, Hazel and Jane Wilbur (2014) Compendium of accessible WASH technologies. WEDC, WaterAid, SHARE

Kira, Alexander (1976) The Bathroom Book. Penguin; New e. edition (28 Oct. 1976)

McMahon S., Caruso B. A., Obure A., Okumu F., Rheingans R. D. 2011 Anal cleansing practices and faecal contamination: a preliminary investigation of behaviours and conditions in schools in rural Nyanza Province, Kenya. Tropical Medicine \& International Health 16, 1536-1540

NHS Direct: http://nhwdenver.com/straining-to-defecate/ [Accessed $10^{\text {th }}$ August, 2017]

Oxford Dictionary (2010)

Rad, Saeed. (2002) Impact of ethnic habits on defeco graphic measurement. Arch Iranian Med 2002; 5 (2): $115-117$

Rosenboom, Jan Willem., Cordell Jacks, Kov Phyrum, Michael Roberts and Tamara Baker (2011) Sanitation marketing in Cambodia. January 2011. Waterlines Vol. 30 No. 1

Sakakibara, Ryuji., Kuniko Tsunoyama, Hiroyasu Hosoi, Osamu Takahashi, Megumi Sugiyama, Masahiko Kishi, Emina Ogawa, Hitoshi Terada, Tomoyuki Uchiyama, and Tomonori Yamanishi. Influence of Body Position on Defecation in Humans. Lower Urinary Tract Symptoms LUTS (2010) 2, 16-21 Blackwell Publishing Asia Pty Ltd

Sidibe, Myriam and Val Curtis (2007) Can hygiene be cool and fun? Insights from school children in Senegal (English). World Bank

http://documents.worldbank.org/curated/en/765011468307739863/Can-hygiene-be-cool-and-funInsights-from-school-children-in-Senegal [Accessed $10^{\text {th }}$ August, 2017]

Sikiov, Dov (2003) Comparison of Straining During Defecation in Three Positions Results and Implications for Human Health. Digestive Diseases and Sciences, Vol. 48, No. 7 (July 2003), pp. 1201$1205\left({ }^{\circ} \mathrm{C} 2003\right)$

Sugden, Steven (2014) Latrine Design: Go in Peace. Waterlines Vol. 33 No. 3 July 2014

UN, 20152030 Agenda: http://www.globalgoals.org/global-goals/clean-water-sanitation/ [Accessed $10^{\text {th }}$ August, 2017]

von Münch, E. Milosevic, D. (2015). Qualitative survey on squatting toilets and anal cleansing with water with a special emphasis on Muslim and Buddhist countries by using the SuSanA discussion forum. Ostella Consulting, Schwalbach, Germany

Williams, Jesse Feiring \& Gloyd Gage Wetherill (1950) Personal and Community Hygiene Applied. Saunders

World Bank Group (2015) Rural Sanitation Market Expansion of Domestic Private Sector in Indonesia, Washington DC: World Bank.

WSP (2005) Hygiene, Sanitation and Water Toolkit. World Bank https://www.wsp.org/HygieneSanitation-Water-Toolkit/BasicPrinciples/AnalCleansing.html [Accessed $10^{\text {th }}$ August, 2017] 